\title{
PRÁTICAS RELIGIOSAS E REDES SOCIAIS OS NOVOS ESPAÇOS E TEMPOS DA IGREJA CATÓLICA EM PORTUGAL
}

\section{RELIGIOUS PRACTICES AND SOCIAL NETWORKS THE NEW SPACES AND TIMES OF THE CATHOLIC CHURCH IN PORTUGAL}

\author{
Margarida Franca \\ CITER - Centro de Investigação de Teologia e Estudos da Religião, Universidade Católica Portuguesa; \\ Departamento de Geografia e Turismo, Faculdade de Letras, Universidade de Coimbra \& CEGOT - Centro de \\ Estudos de Geografia e Ordenamento do Território. Largo Porta Férrea, 3000-370 Coimbra, Portugal. Email: \\ margfranca@gmail.com
}

\begin{abstract}
Rui Martins
Departamento de Geografia e Turismo, Faculdade de Letras, Universidade de Coimbra \& CEGOT - Centro de Estudos de Geografia e Ordenamento do Território. Largo Porta Férrea, 3000-370 Coimbra, Portugal. Email: ruim66@gmail.com
\end{abstract}

\section{João Luís J. Fernandes}

Departamento de Geografia e Turismo, Faculdade de Letras, Universidade de Coimbra; CEIS20 - Centro de Estudos Interdisciplinares do Século XX \& CEGOT - Centro de Estudos de Geografia e Ordenamento do Território. Largo Porta Férrea, 3000-370 Coimbra, Portugal. Email: jfernandes@fl.uc.pt

\begin{abstract}
Resumo: No contexto da modernidade líquida ou da hipermodernidade os conceitos geográficos de espaço, território e comunidade estão num processo de mudança. A par da identidade estes são definidos pela sua fragmentação, instabilidade, ambivalência, hibridismo e de multipertenças, onde se misturam escalas, dimensões, fluxos, direções e nós de ligação.

Com efeito, as novas tecnologias de informação e de comunicação, onde se incluem as redes sociais online, são exemplos de meios e mecanismos que favorecem o aparecimento de novas sociabilidades, espacialidades e temporalidades, de onde a religião não se exclui. Neste campo, a Igreja Católica, propõe a sua incorporação nas práticas e experiência de fé, balançando entre uma perspetiva otimista da utilidade das redes virtuais e da propagação do território de fluxos e das comunidades religiosas extraterritoriais e uma perspetiva menos otimista face à primeira, da necessidade de reforço do poder dos lugares sagrados e das relações presenciais "face a face" numa comunidade física.
\end{abstract}

Palavras-chave: multiterritorialidades, redes sociais online, comunidades transterritoriais.

\begin{abstract}
In the context of liquid modernity or hypermodernity, the geographical concepts of space, territory and community are under a process of change, being now characterized by their fragmentation, instability, ambivalence, hybridism and multi-belongings. Indeed, space, territory and community, just like the concept of identity, mix scales, dimensions, flows, directions and link nodes.

In fact, new information and communication technologies, including online social networks, are examples of means and mechanisms that favor the emergence of new sociabilities, spatiality and temporality, from which religion is not excluded. In this context, the Catholic Church proposes the incorporation of online social networks into the practices and experience of faith. Our data shows a balance between an optimistic perspective pointing the usefulness of virtual networks, the spread of flows territory and extraterritorial religious communities and a less optimistic perspective against this
\end{abstract}


previous one, underlining the need to strengthen the power of sacred places and face-to-face relationships in a physical community.

Keywords: multiterritorialities, online social networks, transterritorial communities.

\section{Introdução}

Tendo como referência geral o padrão das sociedades ocidentais, assistimos a mudanças relevantes que passam pela mobilidade espacial, pelo aumento das trocas e das interdependências e por reconfigurações na relação dos sujeitos com o local e com as comunidades às quais pertencem, hoje marcadas por uma maior abertura. Tudo isto tem reflexos na diversidade de práticas em múltiplos domínios, como a religião, facto que vai ao encontro do que Rogério Haesbaert (2004) define por multiterritorialidade. Esta consiste na conjugação de múltiplas vivências, articulando diferentes dimensões do espaço geográfico. Por um lado, os espaços contínuos, as geografias das velhas materialidades e distâncias euclidianas, bem expressas na continuidade da frequência de lugares religiosos. Por outro, as espacialidades organizadas em redes topológicas, que promovem relações condicionadas pela conetividade tecnológica e pelas relações à distância em muito intermediadas por novas métricas de acessibilidade e pelo reequacionamento dos conceitos de proximidade e distância. A internet, as redes sociais e as sociabilidades digitais inovadoras, não se substituindo nem se sobrepondo às velhas relações de proximidade geográfica, acabam por tornar estas vivências mais híbridas e flexíveis.

É nesta perspetiva que devem ser trazidos ao debate as dinâmicas de reconfiguração das velhas comunidades que intermediavam, acolhiam e agregavam a pessoa e a família. Já no século XIX, Ferdinand Tönnies (2001), perante a vaga de industrialização, se questiona sobre a decomposição da denominada comunidade (Gemeinschaft), definida pela proximidade entre indivíduos com elevado grau de afinidade, interesses comuns, destinos partilhados e normas assumidas por grupos nos quais seriam mais elevados os níveis de solidariedade e identificação. É a esta organização mais fechada e nuclear que o sociológico Mark Granovetter (1973) associou os termos strong ties, os laços fortes que unem os indivíduos pela semelhança e por filiações mais duradouras.

O próprio Tönnies (2001), numa obra com edição original de 1887, entendendo as mudanças trazidas pelas novas realidades sociais e económicas, avançou com o conceito de sociedade (Gesellschaft) mais próximo da ideia de sociedade e dos weak ties referidos por Granovetter (1973). Nesta nova perspetiva, as práticas sociais e as espacialidades estão sobretudo marcadas pelas relações mais ocasionais, entre 
atores não semelhantes unidos por filiações transitórias e interesses também mais fluídos.

É nesta sequência, no sempre difícil equilíbrio entre a comunidade e a sociedade, que se define o objetivo central deste trabalho: debater o papel que as novas tecnologias de comunicação e informação, em particular as redes sociais online, podem, no que à religião diz respeito, auxiliar a manter os laços de contacto entre as populações agora mais dispersas e em movimento. Havendo agora maiores dificuldades para a partilha e o encontro nos velhos espaços de culto, questiona-se como pode o mundo digital ser um fator de compensação. Deste modo, problematiza-se até que ponto a internet poderá contribuir para os fatores centrífugos de separação ou, pelo contrário, poderá atenuar os efeitos da distância e das mobilidades espaciais que afetam as comunidades de crentes, que assim se poderão recompor.

Para além disso, será importante questionar até que ponto, numa época na qual as novas tecnologias estão omnipresentes, se fazem sentir também nas práticas e nos comportamentos religiosos, aqui entendidos na forma como as comunidades agora se mantêm, ou não agregadas e no modo como a mensagem religiosa é transmitida, de modo presencial ou, à distância, com a intermediação das redes sociais online.

Se é verdade que a industrialização, o foco de Tönnies na obra oitocentista (e traduzida numa versão de 2001), foi um fator de mudança, é também certo que a velocidade trazida pelas vivências urbanas e, sobretudo, pelas novas tecnologias de informação e comunicação, com impactes agora estudados na denominada dromologia (Virílio, 2006), têm aumentado a transitoriedade e trazido uma plasticidade líquida (Bauman, 2000), pondo em causa a utopia de uma comunidade sustentada pela segurança de um lar e de um sentido de pertença e reconfigurando comportamentos no âmbito das quais se devem equacionar e interrogar as novas práticas, em domínios como a religião.

Pelo contrário, as múltiplas pertenças e os fatores de desagregação aumentam o caráter efémero, transitória e líquido (Bauman, 2000) de muitas realidades sociais facto que se poderá traduzir em novos comportamentos religiosos, mais ou menos intermediados pelas novas tecnologias de informação e comunicação.

Estas novas identidades multiterritoriais, e regressamos ao conceito de Rogério Haesbaert (2004), articulam e fazem a síntese entre múltiplos lugares e escalas geográficas. Daqui pode resultar a progressiva construção de novas topoligamias, isto é, a afirmação de identidades de filiação a múltiplos lugares, de sujeitos circulando numa base social mais flexível e líquida, entre múltiplas comunidades que se vão compondo e recompondo, num processo personalizado, muito diferente em cada um dos atores sociais, coletivos e individuais. Também nesta perspetiva se 
devem interrogar as novas práticas religiosas, problematizando até que ponto se espelham nestas mudanças que atravessam as múltiplas dimensões da vida social e individual.

Enquanto objeto de análise, será importante equacionar em que grau, e sentido, os comportamentos na esfera do religioso estão agora intermediados por aquilo que Lipovetsky e Serroy (2010) identificaram como o ecrã global e omnipresente, o interface permanente entre o sujeito e a realidade, cada vez mais definida pelos códigos binários da digitalização, que se representa por interfaces individuais e coletivos, móveis e fixos, dos painéis televisivos e de grandes dimensões expostos nos espaços públicos e privados, em ambiente indoor mas também, cada vez mais, em contexto outdoor, aos dispositivos individuais, em muito simbolizados pela presença constante do smartphone.

Autores como Daniel Innerarity (2016) têm discutido a realidade contemporânea, mais rápida e difusa, como um processo de desintermediação, isto é, de imediatez e descrença nas tradicionais intermediações, que vão da velha comunidade rural ou de bairro, aos sindicatos e à empresa, mas também à escola, à família e à Igreja. Esta quebra de laços entre o indivíduo e algumas comunidades, entre a pessoa e as instituições que faziam a ponte com o coletivo, a desconfiança e o desejo de desvalorização do 'intermediário', pode estar na origem de alguma fragmentação e atomização social, deixando o sujeito entregue a si próprio, algo relevante em tempos de incertezas e volatilidades ou, como referem Rodrigues e Santos (2018), de uma turbulência derivada do contexto VUCA (Volatilidade, Incerteza, Complexidade e Ambiguidade).

Este risco de maior isolamento vai ao encontro do que Gilles Lipovestky (2004) denominou como tempos hipermodernos, caraterizados por tendências de fundo como a expansão dos mercados, o aprofundamento das tecnologias e a propensão para o individualismo.

Com efeito, no decorrer do processo de globalização e de desenvolvimento científico, tecnológico, eletrónico e cibernético, acentuado nos séculos XX e XXI, ocorre a desconstrução dos conceitos e das estruturas primordiais da sociedade, das quais se destaca o espaço, o tempo, a identidade e a comunidade. No contexto geográfico, esta mudança implicou novas territorialidades.

A consolidação do território virtual e da cultura digital através da "Cibercultura" (Levy, 1997) e da sociedade em rede através da "Galáxia da Internet" (Castells, 2001) ocorre a partir da inexistência de uma base espacial definida, da diminuição das distâncias e do aumento da velocidade e do acesso à informação. Por via deste contexto ocorre a reformulação das temporalidades e das espacialidades, implicando uma nova identidade relacional (Neto, 2017), permitindo uma 
experiência qualitativamente diferente de estar no mundo (Washbourne, 2009), sendo distinto o modo de aprendizagem, de compreensão e de organização em sociedade.

O pós-estruturalismo desconstruiu a realidade espacial acrescentando, à visão euclidiana de espaço fixo e definido por fronteiras e limites estáveis, um espaço diferente e mutável. Está em causa a transgressão do fixo, dos limites lineares, das categorias estanques e dos fluxos espaciais não-hierárquicos que criaram descontinuidades, novas estruturas espaciais com divisões alternativas e novas formas de representação cartográfica como o território-rede ou o território flexível, caracterizado pela sobreposição sucessiva ou concomitante de diferentes espaços multifuncionais e multi-identitários, com diferentes dimensões, escalas, interações espaciais e temporais (Haesbaert, 2004).

A renovação geográfica, neste contexto de múltipla organização territorial, tem subjacente a teoria de compressão espaço-tempo e do sentido global de lugar (Massey, 1994), possibilitando a multiterritorialidade dos fenómenos sociais. A nova base territorial incorpora as noções de mobilidade transnacional, nós interligados, conexões de fluxos, redes de ligação, cultura híbrida e identidades fragmentadas e topoligâmicas (Beck, Giddens e Scott, 1997).

Nesta teia de interdependências e mudanças, a análise espacial tem em consideração não só os atores individuais e as comunidades isoladas, mas também o ser humano conectado com outros seres ou com comunidades numa lógica de descontinuidade espacial. Há contextos e movimentos mais amplos e uma vida social complexa que se desenrola do espaço local para o global, dando estrutura às comunidades transterritoriais (Teixeira, 2017). Na atualidade, o maior acesso, flexibilidade, velocidade e instantaneidade com que as relações ocorrem, permitiu reconfigurar as sociabilidades e as comunidades, cada vez mais distendidas no espaço, fragmentadas, descontínuas, itinerantes ou nómadas (Teixeira, 2011), dando corpo ao "andarilho" de Simmel (1971) ou aos sucessores do "peregrino" de Bauman (2007).

Milton Santos, Maria Souza e Maria Silveira analisam esta nova realidade do território e reforçam as suas verticalidades formadas por pontos distantes uns dos outros, mas ligados por todas as formas e processos sociais (Santos, Souza e Silveira, 1998). Manuel Castells reforça esta ideia com algum otimismo, referindo-se à passagem das comunidades físicas, espaciais e reais às comunidades virtuais ou sociedades em rede definidas pelos espaços de fluxos, pelo tempo atemporal, pela linguagem digital universal, pela realidade virtual implicando uma nova cultura, um novo paradigma comunicacional e uma diferente forma organizacional e relacional (Castells, 2007).

Significa que as novas tecnologias, em particular a internet, têm propriedades tecnológicas e culturais que possibilitam a interatividade dos lugares, organizados 
em redes e geradores de fluxos. Ao nível das sociabilidades, as comunidades em rede permitem a integração noutros grupos, para além daqueles que têm uma base territorial definida e que porventura frequentam com regularidade. Estes grupos ou comunidades organizadas em rede possibilitam ao mesmo tempo estabelecer laços interpessoais que proporcionam outras sociabilidades, apoio, informação, um sentimento de pertença e uma identidade social (Neto, 2017).

Castells analisa o que entende ser o individualismo em rede, não no sentido de isolamento social, mas no sentido de privatização ou de personalização das próprias comunidades. Ou seja, cada um é autónomo e pode reconfigurar as suas próprias redes sociais, baseadas em interesses, valores, afinidades e projetos individuais. Os meios de comunicação, como a internet ou os telemóveis, por exemplo, têm um papel ativo nas sociabilidades, uma vez que permitem fortalecer quer os laços débeis, pouco duradouros ou que não chegam a ocorrer, quer os laços fortes, mais estáveis mesmo à distância (Castells, 2007; Neto, 2017).

Por isso, enquanto objeto do presente artigo, procuramos identificar e caracterizar as comunidades religiosas que incorporam as redes sociais online nas suas experiências quotidianas. É igualmente relevante aferir se estes contextos inovadores abrem novos caminhos de interação e promovem novas sociabilidades mais complexas, híbridas e articuladas, mesmo no domínio do comportamento religioso. Por forma a avaliar este objeto de estudo recorreu-se à análise de dois inquéritos realizados em momentos diferentes, 2014 e 2018 e em escalas diferentes, na cidade de Coimbra (Diocese de Coimbra) e em Portugal, respetivamente. A partir da análise da questão das atividades religiosas associadas à prática religiosa dos inquiridos no inquérito de 2014, ganhou relevância o uso das novas tecnologias no contexto das práticas mais convencionais. Face à consciência da evolução tecnológica entretanto ocorrida e a sua utilização pelos diferentes públicos, realizou-se um novo inquérito apenas focado nesta temática, permitindo, em simultâneo, uma comparação dos valores obtidos embora com outras desagregações geográficas. As dificuldades sentidas prenderam-se com a representatividade e a comparabilidade dos dados, uma vez que o último inquérito se enquadra numa investigação exploratória.

\section{Reconfiguração das identidades religiosas no contexto português. As práticas religiosas e o uso das novas tecnologias}

Em Portugal, as mudanças ocorridas na estruturação das identidades e das comunidades, em particular as religiosas, tem o seu contexto, tendo sido apontados como dois fatores decisivos para a mudança da estrutura social, económica, política e até 
geográfica, dos comportamentos e das mentalidades: as alterações ocorridas após o 25 de abril de 1974 e a integração de Portugal na Comunidade Europeia a 1 de janeiro de 1986. Neste período, a população portuguesa conheceu "alterações significativas ao nível das condições de vida, da organização da família, do funcionamento do mercado de trabalho, do posicionamento internacional do país e dos estilos de vida, suscitando, direta ou indiretamente, a modernização crescente dos comportamentos demográficos portugueses" (Ferrão, 2005, p. 55).

Assiste-se, no início dos anos de 1990, ao uso generalizado da televisão, ao aumento da escolarização, à integração de Portugal nos circuitos turísticos europeus, à crescente urbanização e terciarização dos modos de vida e à crescente entrada de população estrangeira para residir no país, tornando-se num dos veículos de partilha de diferentes comportamentos e mentalidades, mas também de múltiplas identidades culturais e religiosas. Esta tendência para a fixação de população estrangeira residente no nosso país mantém-se constante no século XXI. Em 2016, o Instituto Nacional de Estatística (INE) e o Serviço de Estrangeiros e Fronteiras (SEF) indicaram que 3,8\% (392.969 indivíduos) da população residente em Portugal tinha outra nacionalidade (Ribeiro, 2017). Em 2017, com 421.711 indivíduos estrangeiros, manteve-se este movimento de acréscimo, aumentando $6 \%$ em relação ao ano anterior coexistindo, no país, cerca de 180 nacionalidades diferentes (Oliveira e Gomes, 2017).

Nesta realidade social e geográfica em mudança, acresce o aumento dos casamentos civis e das uniões de facto, face aos casamentos católicos, e o aumento significativo do número divórcios que são causa e consequência da alteração da estrutura familiar. Na atualidade, são comuns os núcleos monoparentais, as famílias recompostas ou as famílias com apenas 1 ou 2 filhos. Altera-se também, de forma significativa, o papel da mulher na estrutura familiar, mas também na sociedade em geral, assumindo a liderança, por exemplo, na população com o ensino superior completo (INE, 2011).

Na contemporaneidade, a identidade religiosa da população portuguesa continua a ser marcada por uma matriz cristã. À escala global, Portugal é um dos países com a mais baixa taxa de diversidade religiosa (Pew Research Center's Forum on Religion \& Public Life, 2014). A população católica, não obstante, ter registado um ligeiro decréscimo entre 2001 e 2011, retoma os valores percentuais de 1981 e fixa-se em $81 \%$, nos censos de 2011 (INE, 1981, 2011). De referir que a questão sobre a religião nos censos apresenta-se de caráter opcional e aplicada no final do questionário, pelo que os valores não são representativos de toda a população recenseada.

Em termos nacionais, assiste-se nas últimas décadas, ao aumento percentual da população católica na região do Alentejo, à estabilização nas regiões do Norte e 
Centro do país e à diminuição nas regiões da Área Metropolitana de Lisboa e do Algarve. As Regiões Autónomas continuam a ter as maiores percentagens de população católica, superando em mais de 10 pontos percentuais a média nacional (INE, 1981, 1991, 2001, 2011).

Este valor representa a geografia, a história, a tradição e a memória individual e coletiva que está simbolicamente associada à própria identidade da sociedade portuguesa (Barreto, 1995).

Não obstante, nos últimos anos Portugal ganhou a imagem de uma sociedade, cada vez mais aberta a outras identidades e culturas, reflexo de uma sociedade plural, híbrida e fragmentada, onde ocorre, em alguns contextos urbanos, a partilha de valores, comportamento, atitudes e crenças religiosas (multi-identidades). A sociedade portuguesa tornou-se diversificada em termos culturais, étnicos e religiosos, pese embora algumas heterogeneidades espaciais (Teixeira, 2012; Vilaça, 2006). De referir que, entre 1981 e 2011, os grupos minoritários passaram de 1,5\% para 3,9\% da população, com particular destaque para o crescimento dos protestantes e de outros grupos cristãos (INE, 1981, 2011), onde se incluem, entre outras, as igrejas históricas (Presbiteriana, Metodista, Lusitana e Luterana), as igrejas evangélicas (Batistas, Assembleia de Deus, Congregação Cristã, entre outras) e algumas mais recentes, de natureza pentecostal e neopentecostal, como a Igreja Universal do Reino de Deus e a Igreja Maná (Vilaça, 2013; Vilaça e Oliveira, 2019). Importa acrescentar que, em 2018 e no contexto apenas da Área Metropolitana de Lisboa (AML), as minorias religiosas atingiam o valor significativo de $9,2 \%$ da população residente (Teixeira, Vilaça, Moniz, Coutinho, Franca e Dix, 2019)

Com efeito, pelas dinâmicas das suas sociabilidades e territorialidades recentes, Portugal tem-se alinhado com a ideia de pós-modernidade, associando-a à pluralidade e à presença de culturas não hegemónicas (Berry, 1984), mas também com a já referida hipermodernidade (Lipovestky, 2004), aqui entendida como sinónimo de avanço do mercado, da tecnologia e de diferentes formas de atomização social, tudo muito intermediado pelo aumento do consumo.

Em termos de valores e de práticas sociais, há tendências muito concretas de autonomia e de liberdade individual (Appadurai, 2004 e Bauman, 2007), sendo que os crentes estão, cada vez mais, a emancipar-se das instituições e das respetivas formas de integração. Veja-se que entre 1981 e 2011 a população sem religião passa de $3,2 \%$ para $6,8 \%$, registado neste período censitário um crescimento percentual muito significativo (INE, 1981, 2011). Os dados mais recentes para a AML apontam um valor 21,8\% de população sem religião, onde se incluem os indiferentes, agnósticos e ateus, e 13,1\% de população crente sem religião (Teixeira, Vilaça, Moniz, Coutinho, Franca e Dix, 2019). 
Ao mesmo tempo, ocorre a erosão de muitos valores conservadores, refletindo-se na mudança dos estilos de vida, mais centrados num espaço individual e independente, sendo evidente a diminuição da população católica praticante e comungante $\left(\mathrm{CEP}^{1}\right)$, e uma maior autonomia da doutrina católica no contexto da celebração do casamento, da estrutura familiar ou mesmo de outras questões mais fraturantes com conteúdos que vão contra a doutrina oficial católica como o aborto, a procriação medicamente assistida, o casamento entre pessoas do mesmo sexo, a eutanásia e a questão da identidade de género. Estamos, pois, perante a desfiliação religiosa, em particular das novas gerações, à pluralização do campo religioso e à reconfiguração das atitudes religiosas e morais (Vilaça e Oliveira, 2019)

Assiste-se, em simultâneo, à perda de influência da religião nos comportamentos individuais e coletivos e fidelizações sociais (secularização e laicização da sociedade) e ao fim de um modelo de práticas religiosas mais institucionalizadas, reguladas e intermediadas pela Igreja Católica. Esta alteração é também causa e consequência da aceitação da diversidade e do pluralismo religioso, onde convivem, no nosso país e em particular nos contextos mais urbanos e cosmopolitas, diferentes identidades e pertenças religiosas, muitas vezes filiados em sistemas ou movimentos religiosos distintos.

O aparecimento de novas práticas, novos lugares sagrados ou redes de territórios sagrados, favoreceu a emergência de novas formas de interação e de integração em comunidade, tendo as novas tecnologias de informação e comunicação contribuído para esta mudança, também em Portugal, de uma forma significativa.

No contexto da reformulação das identidades e da alteração das espacialidades e temporalidades, uma das grandes mudanças dos séculos XXe XXI é o aumento do uso das tecnologias de informação e de comunicação por parte das famílias portuguesas. Segundo o INE, em 2017, 77\% das famílias tinham acesso à internet e $76 \%$ acedem por banda larga. Em termos geográficos, o acesso à internet em casa é mais frequente nas famílias residentes na Área Metropolitana de Lisboa (86\%) e nas famílias com crianças (97\%). Está cada vez mais generalizado o uso desta tecnologia para os estudantes, os jovens até 34 anos e as pessoas que concluíram o ensino superior (INE, 2017).

Para o estudo em causa importa ainda dar conta que, também segundo o INE (2017), o acesso à internet em mobilidade (fora de casa e do local de trabalho e em equipamentos portáteis através do telemóvel ou smarthphone) é uma realidade para 79\% dos utilizadores em 2017. Este indicador continua a evidenciar uma tendência de crescimento.

No contexto europeu (EU-28), as sociedades tecnológicas, onde se inclui Portugal, o aparecimento de uma linguagem digital universal e o alargamento transversal do uso das novas tecnologias de informação e comunicação, em quase todos os 
momentos da vida quotidiana, teve consequências também no campo da religião, nas relações de pertença com as comunidades e nas práticas e vivências religiosas. Este impacto tem particular incidência junto dos nativos digitais que estão mais disponíveis, à espera dos fluxos comunicacionais e informacionais multissensoriais.

Isto compreende também, de forma generalizada, uma resposta teológica e eclesial às novas realidades vividas na sociedade em rede, uma vez que se desenvolveram novas redes, novos mecanismos e novos canais de comunicação virtuais que possibilitaram criar outras formas de experimentar, viver e sentir a fé, misturando, em muitas situações, as escalas do público e privado ou mesmo, local e global. Consolida-se uma comunidade extraterritorial, dando importância aos meios de comunicação como o principal instrumento de informação e formação, de guia e de inspiração dos comportamentos individuais, familiares e sociais.

A rádio, a televisão e a internet, incluindo as redes sociais, com destaque para a página de internet da Santa Sé e das ligações ao Facebook, Youtube, Instagram e Twitter do próprio Papa Francisco, ou no caso de Portugal, da Conferência Episcopal Portuguesa e das páginas da internet das várias dioceses portuguesas ou dos vários movimentos católicos, criaram um novo paradigma comunicacional, outras espacialidades e temporalidades, através das quais é possível participar, com liberdade e autonomia, em diferentes rituais vividos de forma individual ou coletiva, em diferentes contextos, espaços e tempos. Permitiram participar em distintos momentos de oração, tornando presente o mundo do sagrado nos mais diversos lugares da vida quotidiana dos crentes. Desde a casa ao local de trabalho ou nos cafés e centros comerciais, é possível encontrar formas de relação entre os indivíduos e as diferentes comunidades religiosas.

O site "Passo a Rezar", que nasceu em fevereiro de 2010, é uma iniciativa do Secretariado Nacional do Apostolado da Oração, uma obra da Companhia de Jesus (Jesuítas), que se dedica à promoção da oração pessoal. Neste website são disponibilizadas, diariamente e através das suas aplicações móveis, ficheiros que podem ser descarregados e ouvidos a partir de qualquer dispositivo eletrónico que suporte o formato mp3. Estes ficheiros são meditações áudio a partir dos textos da liturgia do dia. Desde o seu início até março de 2018 este site contava já com 128 mil visitantes e cerca de 100 mil utilizadores, nas várias plataformas (Facebook, SoundCloud), sendo apurado um valor de 6 mil utilizadores diários, contados pelos "plays" no SoundCloud dos "passos diários" ou "passos para mais" e downloads do zip de toda a semana².

De referir que a importância atribuída às modernas formas de comunicações, no contexto da Nova Evangelização, não é um dado recente, uma vez que desde 1967 foi institucionalizado o Dia Mundial das Comunicações Sociais. Assim, a 
Igreja Católica tem dedicado, até aos dias de hoje, a sua atenção para a interação entre temas como a imprensa, a rádio, a televisão, o cinema, a publicidade e a internet e os temas, também fundamentais, como a família, os jovens, a mulher ou os direitos do homem, entre outros.

O Papa João Paulo II, em 1992, na IV Conferência Geral do Episcopado Latino-Americano ${ }^{3}$ escreve:

sendo a comunicação entre as pessoas um admirável elemento gerador de cultura, os modernos meios de comunicação social revestem neste campo uma importância de primeira grandeza. Intensificar a presença a Igreja no mundo da comunicação há de ser uma das vossas prioridades.

Também o Papa Bento XVI, em 2003, na $47^{\mathrm{a}}$ mensagem para o Dia Mundial das Comunicações Sociais ${ }^{4}$ refere:

desejo oferecer-vos algumas reflexões sobre uma realidade cada vez mais importante que diz respeito à maneira como as pessoas comunicam atualmente entre si; concretamente quero deter-me a considerar o desenvolvimento das redes sociais digitais que estão a contribuir para a aparição duma nova ágora, duma praça pública e aberta onde as pessoas partilham ideias, informações, opiniões e podem ainda ganhar vida novas relações e formas de comunidade.

Atente-se também a mensagem do próprio Papa Francisco, em 2016, ao reconhecer as vantagens das novas tecnologias e admitir que a internet, as redes sociais e as mensagens de texto são um "presente de Deus", acrescentado ainda que a internet pode ser usada para construir uma sociedade saudável e aberta (Diário de Notícias, 22 janeiro de 2016). Mais recentemente, em junho de 2018, o Papa Francisco publica, na Rede Mundial de Oração, um vídeo (Agência Eclésia, 2018) onde reforça a importância do digital e das redes sociais na construção de uma cidadania em rede como um lugar rico em humanidade, desafiando os católicos a criarem uma rede digital que respeite a integridade e a dignidade humana, que favoreça a solidariedade e o respeito pelo outro na sua diferença. Conclui que "a internet é um dom de Deus e também uma grande responsabilidade".

Não obstante este reforço positivo e otimista da utilidade das redes sociais, o Papa Francisco não deixa de lado o contacto com a comunidade física, a relação de proximidade com os outros elementos da Igreja, a presença e a comunhão na eucaristia e a obrigatoriedade de encontro pessoal no dia a dia ou ao domingo. Isto porque, tal como no contexto mais geral, está em causa o risco de alienação, de manipulação, de perda de valores de transmissão e perpetuação, de esvaziamento de relações e de isolamento. Porventura, poderá culminar na ausência de 
pertença a uma comunidade muito concreta e física (Neto, 2017), no risco de perda do sentido da existência individual e coletiva (Santos, Souza e Silveira, 1998), na perda da "segurança ontológica" (Giddens, 1991), na dissolução dos laços afetivos e sociais, no surgimento de novas fronteiras de poder e no reforço dos sentimentos de egoísmo, exclusão, desapego e individualismo, que a sociedade de risco pôs a descoberto.

\section{Metodologia}

O estudo que aqui se apresenta tem como ponto de partida um inquérito realizado em 2014, correspondente à componente empírica de um trabalho de investigação em geografia humana. Este estudo focou-se na expressão territorial da identidade religiosa da população católica praticante, na diocese de Coimbra.

A escolha dos momentos de realização do inquérito foi orientada para um universo estatístico de conveniência. Não se utilizou o quadro de números aleatórios uma vez que, para se obter uma amostra significativa, foi necessário escolher o dia de maior afluência à missa, que consideramos ser o domingo.

Para além disso, para evitar desvios de exceção, os inquéritos foram realizados fora de atos sociais, como batizados, casamentos ou funerais. Presencialmente, foram questionados, de forma aleatória, homens e mulheres, jovens a partir dos 15 anos e adultos. A idade mínima da população inquirida foi ponderada tendo em conta o critério apresentado, desde 1980, pelo INE à questão da religião, que selecionou apenas a população acima dos 15 anos de idade. Foi considerada também que, a partir desta idade, a população terá um envolvimento mais consciente e uma prática religiosa mais desprendida das opções familiares. Nesta fase da vida, muitos dos fiéis já possuem o crisma e estão envolvidos em atividades e grupos religiosos como, entre outros, os escuteiros, a catequese para jovens/adultos ou as viagens e os campos de férias com cariz religioso.

Este inquérito foi realizado, presencialmente, nos dias 2, 9, 16, 23 e 30 de março de 2014. Foi dirigido para a população que assistia à eucaristia dominical em sete igrejas da cidade de Coimbra (Diocese de Coimbra), com a realização de 55 inquirições em cada uma, totalizando 385 inquéritos validados. Tendo em conta a Tabela de Krejcie e Morgan (1970), a amostra foi representativa da população católica praticante da diocese de Coimbra, atingindo um grau de confiança de $95 \%$ e uma margem de erro de $5 \%$. O valor de base e total da população católica praticante na Diocese de Coimbra teve como fonte o quantitativo apurado pela Conferência Episcopal Portuguesa no recenseamento à prática dominical naquela diocese, em 9 de março de 2001 (106.595 indivíduos). 
Este inquérito incluía os seguintes grupos de questões: 1) dados do inquirido; 2) descrição da prática religiosa do inquirido (onde foi extraída a questão objeto de estudo deste artigo) e 3) identificação dos lugares sagrados de pertença à escala local, nacional e internacional.

Por forma a atualizar a informação que já possuímos, mas também para alargar o espectro da nossa abordagem, realizámos em 2018 um novo inquérito exploratório, enviado por correio eletrónico e através das redes sociais online (Facebook e WhatsApp), entre os dias 29 de abril e 6 de maio de 2018, à população católica residente em Portugal. Neste inquérito foi apurada a utilização da internet, no contexto das práticas religiosas, incluindo os mecanismos utilizados, a frequência de utilização, os locais onde se processa a pesquisa e os sites consultados. Para além da análise da evolução numérica do uso destas redes e da caracterização da população que as consulta, procurámos contribuir para um estudo sobre as redes que estão estabelecidas e a noção de comunidade multiterritorial ou transterritorial que poderá estar associada à população católica portuguesa.

Este inquérito enriqueceu a abordagem com uma nova janela de observação sobre a intermediação do digital nas práticas religiosas. Desta vez, os dados não focam uma comunidade inquirida no seu espaço analógico de culto, mas, pelo contrário, faz o levantamento de dados a partir das próprias redes e do espaço digital.

Dos 1.052 inquéritos respondidos, foram validados 908, dos quais $74 \%$ (671 inquiridos) correspondem a população residente nas regiões do Norte, Centro e Área Metropolitana de Lisboa. Não obtivemos uma resposta de todos os concelhos portugueses, sendo que $48 \%$ (433 inquiridos) são residentes nos concelhos do Porto, Coimbra e Lisboa.

\section{Resultados}

No inquérito de 2014, as sete igrejas foram agrupadas em duas tipologias de comunidades religiosas (Tipologia 1 e Tipologia 2), tendo por base as caraterísticas previamente identificadas em cada uma delas, bem como o sentido geral dos resultados obtidos no inquérito efetuado. Para esse efeito, consideraram-se os seguintes fatores distintivos: localização das igrejas na cidade de Coimbra (áreas urbanas consolidadas ou áreas de expansão urbana recente); perfil socioeconómico da população inquirida (idade, habilitações académicas, profissão e rendimentos) e as práticas religiosas e integração na comunidade religiosa (percurso religioso, pertença ou não a grupos paroquiais e frequência na eucaristia). Assim, a Tipologia 1, representa a grosso modo uma comunidade religiosa mais tradicional, convencional e com uma territorialidade interna e local (mais centrada na paróquia de residência 


\section{PERFIL DA POPULAÇÃO}

- Área de residência mais afastada do centro urbano

- População envelhecida e população viúva

- Fragilidades socioeconómicas (habilitações académicas, profissão e rendimentos mais reduzidos)

- População portuguesa e natural de Coimbra

- População que reside há mais tempo na freguesia onde reside atualmente

- População que frequenta semanalmente a mesma igreja e está integrada em grupos da paróquia (católicos militantes)

\section{TERRITORIALIZAÇÃO}

Forte enraizamento na freguesia de residência Forte relação com a paróquia de residência Relação de pertença com o lugar sagrado Laços interpessoais (comunidade) muito fortes

Práticas e vivências mais convencionais e individuais Sociabilidades reduzidas, isolamento e refúgio (reza sozinha)

Mobilidades reduzidas e de maior confinamento

Ruturas no conhecimento e perceção da cidade, do território nacional e internacional

Territorializa ção clássica, centrada num número reduzido de lugares e pouco distendida no espaçotempo

Figura 1 Comunidade religiosa na Diocese de Coimbra: Tipologia 1 (2014)

\section{PERFIL DA POPULAÇÃO}

- Área de residência próxima do núcleo urbano consolidado

- População mais jovem e muitos casais com filhos

- Habilitações académicas superiores e rendimentos elevados

- Alguma diversidade de nacionalidades e proveniência concelhia

- População que reside há menos tempo na atual freguesia de residência

- População que frequenta outras igrejas e está integrada em grupos da paróquia

\section{TERRITORIALIZAÇÃ O}

\section{Menor enraizamento na freguesia de residência}

Fraca relação com a paróquia de residência

Relação de pertena menos intensa com os lugares sagrados ou pelo menos não tão centralizada

Laços interpessoais (comunidade) muito fortes

Sociabilidades alargadas e de maior abertura e partilha

Mobilidades alargadas e mais cosmopolitas

Maior conhecimento e perceção da cidade, do território nacional e internacional

Multiterritorialidades e Territórios-rede: número alargado de lugares e distendida no espaço-tempo (diferentes escalas, dimensões e temporalidades)

Figura 2 Comunidade religiosa na Diocese de Coimbra: Tipologia 2 (2014) 
e no território nacional), agrega a população inquirida nas igrejas de Eiras, Rainha Santa Isabel e S. Martinho do Bispo (Figura 1). A Tipologia 2 representa, por sua vez, uma comunidade religiosa mais cosmopolita e aberta com uma multiterritorialidade assinalável (uso e pertença a uma rede mais diversa de lugares na cidade, no país e no estrangeiro), que agrega a população inquirida nas igrejas da Sé Nova, S. José, Nossa Senhora de Lurdes e S. João Batista (Figura 2).

A primeira tipologia de comunidade religiosa está associada às práticas religiosas mais convencionais, outrora reconhecidas pela sua regularidade e obrigação na presença na assembleia dominical e na frequência da paróquia da freguesia de residência, na sua maioria coincidente com o lugar sagrado onde foram realizados os momentos mais marcantes do percurso religioso dos crentes, como o batismo ou o casamento (forte enraizamento na freguesia e paróquia de residência). Há um percurso vivencial que, em grande parte, se cruza com um percurso religioso. Os laços interpessoais com o pároco e com a comunidade são, neste contexto, fortes, porque se baseiam numa relação intensa emocionalmente, de intimidade, de confiança mútua e de reciprocidade (Granovetter, 1973). As sociabilidades e as mobilidades são reduzidas e de maior confinamento, traduzindo-se numa territorialização clássica e centrada num número reduzido de lugares e pouco distendida no espaço-tempo. Esta é a expressão territorial de uma população católica praticante que reside nas freguesias menos urbanizadas, mais envelhecida, em muitas circunstâncias viúva e a viver sozinha, e com algumas fragilidades relativamente às habilitações académicas e aos rendimentos (Franca, 2016).

$\mathrm{Na}$ atualidade, embora continuem a persistir, mesmo no contexto urbano, este tipo de comunidades centradas e de escala interna e local, assiste-se à sua descompactação. Na segunda tipologia de comunidades religiosas, os crentes, pela sua crescente autonomia e abertura ao "outro" e pelo maior acesso a outros lugares (habilitações académicas superiores, maiores capacidades económicas ou maior acesso a todo o tipo de informação) escolhem os lugares que frequentam, não por questões geográficas (paróquia de residência), mas onde melhor se integram, retirando de cada um deles uma interação muito própria. A múltipla rede de lugares sagrados de pertença (multiterritorialidade e território-rede), da qual fazem parte lugares de diferentes escalas, dimensões ou mesmo de diferentes sistemas religiosos, implica relações de lealdade e pertença menos centralizadoras que no contexto atrás descrito, e por isso, permite sociabilidades de maior abertura e partilha e mobilidades alargadas e cosmopolitas (Franca, 2016).

Tendo em conta as duas tipologias descritas das comunidades religiosas na Diocese de Coimbra, analisa-se na Tabela 1, os dados apurados no inquérito de 2014, relativos às principais atividades religiosas dos inquiridos e as ferramentas 
Tabela 1 Principais atividades religiosas da população inquirida nas sete igrejas da Diocese de Coimbra, por tipologia (2014)

\begin{tabular}{|c|c|c|c|c|c|c|c|c|}
\hline \multirow{3}{*}{$\begin{array}{l}\text { Atividadesde religiosas } \\
\text { associadas à prática } \\
\text { religiosa }\end{array}$} & \multicolumn{3}{|c|}{ Tipologia 1} & \multicolumn{4}{|c|}{ Tipologia 2} & \multirow[t]{2}{*}{ Total } \\
\hline & $\begin{array}{l}\text { Igreja } \\
\text { de Eiras }\end{array}$ & $\begin{array}{c}\text { Igreja } \\
\text { Rainha } \\
\text { Santa } \\
\text { Isabel }\end{array}$ & $\begin{array}{l}\text { Igreja S. } \\
\text { Martinho } \\
\text { do Bispo }\end{array}$ & $\begin{array}{l}\text { Igreja da } \\
\text { Sé Nova }\end{array}$ & $\begin{array}{l}\text { Igreja } \\
\text { de } \\
\text { S. José }\end{array}$ & $\begin{array}{c}\text { Igreja } \mathrm{N}^{\mathrm{a}} \\
\text { Senhora } \\
\text { de } \\
\text { Lurdes }\end{array}$ & $\begin{array}{l}\text { Igreja } \\
\text { S. João } \\
\text { Batista }\end{array}$ & \\
\hline & \multicolumn{8}{|c|}{$\%$} \\
\hline Oração & 72,7 & 87,3 & 80,0 & 85,5 & 89,1 & 81,8 & 90,9 & 83,9 \\
\hline Vou à missa & 96,4 & 83,6 & 80,0 & 96,4 & 98,2 & 90,9 & 96,4 & 91,7 \\
\hline Vou a peregrinação & 25,5 & 27,3 & 20,0 & 32,7 & 20,0 & 76,4 & 23,6 & 32,2 \\
\hline $\begin{array}{l}\text { Participo em visitas a } \\
\text { lugares/sítios religiosos }\end{array}$ & 36,4 & 32,7 & 23,6 & 32,7 & 20,0 & 38,2 & 38,2 & 31,7 \\
\hline $\begin{array}{l}\text { Estou inserido em } \\
\text { grupo/comunidade religiosa }\end{array}$ & 29,1 & 32,7 & 7,3 & 34,5 & 20,0 & 52,7 & 36,4 & 30,4 \\
\hline Participo na catequese & 27,3 & 12,7 & 3,6 & 10,9 & 3,6 & 14,5 & 12,7 & 12,2 \\
\hline Leio livros religiosos & 34,5 & 49,1 & 21,8 & 34,5 & 20,0 & 54,5 & 49,1 & 37,7 \\
\hline Ouço músicas religiosas & 30,9 & 23,6 & 16,4 & 34,5 & 34,5 & 34,5 & 36,4 & 30,1 \\
\hline $\begin{array}{l}\text { Pesquiso em sites } \\
\text { multimédia religiosos }\end{array}$ & 14,5 & 20,0 & 5,5 & 27,3 & 16,4 & 41,8 & 34,5 & 22,9 \\
\hline $\begin{array}{l}\text { Participo em acções de } \\
\text { voluntariado }\end{array}$ & 12,7 & 34,5 & 14,5 & 30,9 & 29,1 & 56,4 & 38,2 & 30,9 \\
\hline $\begin{array}{l}\text { Participo em acções } \\
\text { humanitárias/missões } \\
\text { ligadas à religião }\end{array}$ & 3,6 & 10,9 & 3,6 & 9,1 & 10,9 & 16,4 & 14,5 & 9,9 \\
\hline Outras atividades & 12,7 & 7,3 & 3,6 & 7,3 & 5,5 & 7,3 & 25,5 & 9,9 \\
\hline TOTAL & 33,0 & 35,2 & 23,3 & 36,4 & 30,6 & 47,1 & 41,4 & 35,3 \\
\hline
\end{tabular}

utilizadas na sua prática religiosa, onde se incluem os livros, músicas ou, mesmo, a consulta de sites.

Da análise dos resultados obtidos, apurámos a coexistência, mesmo num contexto urbano, de duas situações distintas. Apesar da utilização da internet ter uma expressão pouco significativa, em particular se comparada com outras atividades como a oração, o ir à missa ou participar em peregrinações, é possível aferir que existem diferenças no uso das novas tecnologias por parte dos inquiridos.

$\mathrm{Na}$ tipologia 1, constata-se que a internet é pouco referida tal como a leitura de livros ou a audição de músicas religiosas, a participação em ações de voluntariado ou ações humanitárias. No caso específico da população inquirida na Igreja de S. Martinho do Bispo, por exemplo, apenas $5,5 \%$ da população inquirida pesquisa sites multimédia religiosos e, tal como as outras igrejas incluídas nesta tipologia, a internet parece pouco integrada nas práticas religiosas dos inquiridos.

Na tipologia 2, as comunidades estão alicerçadas, também, pelas redes sociais que permitem uma proximidade eletrónica e consolidam a definição de uma territorialidade múltipla e externa dos inquiridos. Veja-se o caso da Igreja de Nossa 
Senhora de Lurdes onde $41,8 \%$ da população inquirida pesquisa em sites religiosos multimédia, uma experiência comparável com outras mais convencionais, como a visita a lugares religiosos ou mesmo ouvir música religiosa. Esta percentagem é igualmente superior nas outras igrejas incluídas nesta tipologia.

Desta leitura constatámos que a questão da internet não está, ainda, integrada, de forma transversal, nas práticas e atividades religiosas e que o seu uso está associado a diferentes tipologias de comunidades, contribuindo não só apenas fatores geográficos (lugar de residência e paróquia de pertença) mas também fatores sociodemográficos que caracterizam as tipologias de comunidades como a idade, os rendimentos mensais e as habilitações académicas da população inquirida.

Uma vez que o inquérito de 2014 apenas despertou o interesse para o estudo do uso das novas tecnologias e das redes sociais online no contexto das práticas religiosas das comunidades, e da forma como estas se vão adaptando às transformações tecnológicas da contemporaneidade, optámos por realizar um outro inquérito, em 2018, para conhecer, de forma mais detalhada e a nível nacional, a população que recorre à internet ou a mecanismos alternativos online na sua prática religiosa.

Em termos de caracterização, a população inquirida (católica e residente em Portugal), caracteriza-se por $(\mathrm{n}=908)$ :

- população adulta ( $83 \%$ entre os 25 e os 69 anos);

- maioritariamente feminina ( $71 \%$ mulheres);

- nacionalidade portuguesa (93\%);

- população casada (58\%) e a viver com o seu agregado familiar (80\%);

- população com habilitações académicas superiores (77\% com curso superior);

- população que trabalha $(74 \%)$, maioritariamente especialistas das atividades intelectuais e científicas (74\%) e com rendimento mensal entre os mil euros e os três mil euros (53\%);

- população integrada na Igreja Católica e que se assume como "católica praticante" $(80 \%)$.

No que diz respeito à prática religiosa e à relação da população com a igreja, verifica-se que a grande maioria ( $82 \%$ ) dos inquiridos vai à missa pelo menos uma vez por semana, sendo que $61 \%$ frequenta a igreja da sua paróquia de residência. De referir também que $66 \%$ não frequentam sempre a mesma igreja, escolhendo diferentes lugares de culto na sua prática religiosa. A escolha destes lugares está associada a questões geográficas, uma vez que a localização (proximidade do local de trabalho ou residência) é o motivo mais referido, logo seguido do sentimento de integração numa comunidade ou num grupo específico da igreja/paróquia. 
Considerando apenas a questão da missa, constata-se que 55\% não recorre a mecanismos alternativos para assistir à eucaristia, não obstante $16 \%$ utilizar apenas a internet e $11 \%$ recorrer a diferentes canais (rádio, televisão e internet). Estas percentagens revelam que a população começa a diversificar os meios e os contextos de receção da mensagem religiosa. Neste sentido, ainda que sejam necessários estudos adicionais e que este que aqui se apresenta tenha um sentido mais exploratório, as práticas religiosas parecem seguir a tendência geral das sociabilidades e das práticas do quotidiano, que conjugam as interações diretas e indiretas, os contactos de proximidade e os efetuados à distância, a vivência de espaços analógicos, mas também o uso de meios digitais.

No contexto das atividades religiosas, as tarefas como "navegar em páginas de internet religiosas", "utilização de redes sociais (Facebook, Twitter)", "utilização de aplicações móveis", "consulta de blogues religiosos" e "utilização de podcast" são muito referenciadas pelos inquiridos e têm semelhante importância que atividades mais convencionais como consultar e ler livros religiosos, ouvir músicas religiosas, ouvir programas de rádio religiosos, ver programas de televisão religiosos, entre outros (Figura 3).

No que diz respeito ao uso da internet nas práticas religiosas, verifica-se que $72 \%$ dos inquiridos recorre a ferramentas da internet. Embora seja uma participação maioritariamente passiva, uma vez que os inquiridos não são autores de conteúdos e apenas utilizam estas ferramentas para ler ou rezar (94\%), o seu uso é também regular ou muito frequente, uma vez que há uma utilização diária ou mais do que uma vez por semana (63\%). A população inquirida costuma utilizar estas ferramentas em vários lugares (casa, local e trabalho, transportes) e utiliza distintos dispositivos, como o computador, smarthphone ou tablet.

Com o objetivo de identificar as ligações e as redes estabelecidas pela comunidade católica em Portugal, constata-se ainda que a população inquirida possui uma rede de páginas de internet composta por mais de 23 referências, sendo que as mais citadas são: Página Oficial do Vaticano, Evangelho do Quotidiano, Apostolado de Oração, Conferência Episcopal Portuguesa, Click to Pray, Ponto SJ, Secretariado Nacional da Pastoral da Cultural e diversos sites de paróquias, dioceses e arquidioceses. Esta rede, mais do que expressar a opinião, permite à população inquirida estar atualizada, estar ligada a uma comunidade ou estar próxima das outras pessoas.

Para além do território nacional, anteriormente analisado, podemos obter uma outra escala de análise a partir da leitura dos dados do inquérito de 2018, por concelho de residência, em virtude de $43 \%$ ( $n=507)$ dos inquiridos residirem nos concelhos do Porto, Coimbra e Lisboa. 


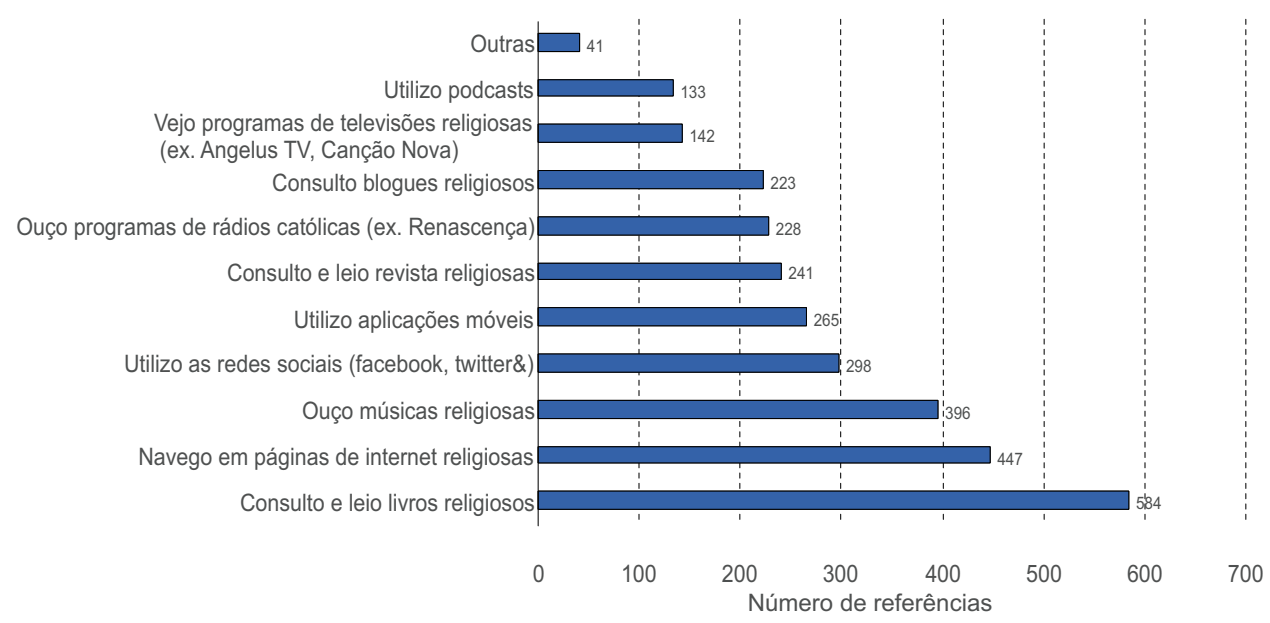

Figura 3 Experiências religiosas mais referenciadas pelos inquiridos (2018)

Nesta escala de análise existem fatores que permitem apontar algumas diferenças no perfil dos utilizadores de internet e das redes sociais, consoante o concelho de residência.

A população católica residente no concelho de Coimbra regista uma menor percentagem (62\%) de população que usa a internet no contexto das suas práticas religiosas e uma menor percentagem de população que usa as redes sociais (29\%) (Tabela 2). Porventura estes dados estão relacionados com algumas características relativas ao perfil da população inquirida, uma vez que este concelho apresenta, relativamente aos outros dois municípios em estudo, uma população mais envelhecida, com rendimentos médios mensais inferiores e com uma percentagem e população com ensino superior também inferior (Tabela 2).

Em termos regionais, constata-se também (Tabela 2) que a população residente na Área Metropolitana de Lisboa é a que apresenta a percentagem mais elevada de população que usa a internet e que usa as redes sociais. Este valor está associado, porventura, também ao perfil da população aí residente pois regista uma maior percentagem de população que aufere mais de três mil euros mensais $(27 \%)$ e uma maior percentagem de inquiridos com curso superior (77\%) (Tabela 2).

Segundo o INE (2018), em termos regionais, a região da Área Metropolitana de Lisboa registava em 2017 a maior percentagem de agregados domésticos com acesso à internet por banda larga (85\%) e uma situação relativa ao rendimento mensal e às habilitações académicas (Tabela 3), o que valida não apenas os dados obtidos nos inquéritos como justifica o maior acesso à internet nesta região de Portugal. 
Tabela 2 Algumas características da população que usa a internet nas suas práticas religiosas (2018)

\begin{tabular}{l|c|c|c|c|c|c}
\hline \multirow{2}{*}{$\begin{array}{c}\text { Área } \\
\text { Geográfica }\end{array}$} & $\begin{array}{c}\text { Dados Inquérito 2018 } \\
+65 \text { anos }\end{array}$ & $\begin{array}{c}\text { Rendimento } \\
\text { superior a } \\
\text { 3000 euros }\end{array}$ & $\begin{array}{c}\text { Curso } \\
\text { Superior }\end{array}$ & $\begin{array}{c}\text { Católicos } \\
\text { Praticantes }\end{array}$ & Uso Internet & $\begin{array}{c}\text { Uso Redes } \\
\text { Sociais }\end{array}$ \\
\cline { 2 - 6 } & \multicolumn{7}{|c}{$\%$} & 74,7 & 34,5 \\
\hline Norte & 12,4 & 6,0 & 75,1 & 90,0 & 84,7 & 35,9 \\
Porto & 12,2 & 8,4 & 87,0 & 92,4 & 64,4 & 30,4 \\
Centro & 13,9 & 5,3 & 79,5 & 84,2 & 61,6 & 28,6 \\
Coimbra & 14,3 & 6,9 & 83,7 & 81,8 & 77,0 & 34,7 \\
AML & 14,5 & 28,6 & 76,7 & 95,0 & 76,9 & 35,8 \\
Lisboa & 13,9 & 15,0 & 86,1 & 94,2 & & \\
\hline
\end{tabular}

Tabela 3 Dados estatísticos de caracterização da população residente

\begin{tabular}{|c|c|c|c|c|}
\hline \multirow{3}{*}{ Área Geográfica } & \multicolumn{4}{|c|}{ Dados INE } \\
\hline & Idade +65 anos $\left(^{*}\right)$ & $\begin{array}{l}\text { Remuneração Base } \\
\text { Média Mensal }\left({ }^{* *}\right)\end{array}$ & Curso Superior $\left({ }^{* * *}\right)$ & $\begin{array}{c}\text { Agregados } \\
\text { Domésticos com } \\
\text { Acesso Internet por } \\
\text { Banda Larga }\left(^{*}\right)\end{array}$ \\
\hline & \multicolumn{4}{|c|}{$\%$} \\
\hline $\begin{array}{l}\text { Norte } \\
\text { Porto } \\
\text { Centro } \\
\text { Coimbra } \\
\text { AML } \\
\text { Lisboa }\end{array}$ & $\begin{array}{l}19,8 \\
28,0 \\
23,8 \\
24,7 \\
21,4 \\
28,4\end{array}$ & $\begin{array}{r}810 \\
1089 \\
787 \\
901 \\
1149 \\
1289\end{array}$ & $\begin{array}{l}12,0 \\
25,3 \\
12,1 \\
26,9 \\
19,6 \\
31,1\end{array}$ & $\begin{array}{l}73,6 \\
72,1 \\
85,0\end{array}$ \\
\hline
\end{tabular}

(*) Dados de 2017

$\left.{ }^{* *}\right)$ Dados de 2013: Remuneração base média mensal dos trabalhadores por conta de outrém

$\left.{ }^{* * *}\right)$ Dados de 2011

Fonte: INE, 2011, 2013, 2018.

\section{Conclusões}

O estudo do uso das novas tecnologias de informação e comunicação e a sua incorporação no âmbito das práticas e das experiências de fé, constitui um possível caminho para a análise da diluição das comunidades religiosas católicas contemporâneas, onde se inclui a alteração das sociabilidades baseadas na vizinhança residencial e numa única comunidade física, e o reforço da complexidade das relações sócio espaciais no espaço urbano, onde se florescem os laços de pertença múltiplos e a fragmentação das práticas do território (Teixeira, 2011).

A comunitarização da Igreja Católica está associada, desde sempre, aos lugares sagrados organizados de forma hierárquica e que vão desde a igreja, à paróquia 
e à diocese. Com efeito esta comunitarização não perdeu o seu peso institucional, embora esteja hoje reforçada pela sociedade em rede e pela consolidação das comunidades virtuais.

De facto, a Igreja Católica, mesmo no contexto de Portugal, tem diversificado os seus meios de circulação e difusão da mensagem, culminando com uma nova "cultura do encontro". O número de páginas de internet, incluindo as aplicações móveis disponíveis, em particular da própria Conferência Episcopal Portuguesa ou das paróquias portuguesas, são um exemplo das prioridades para igreja de definir diferentes canais de comunicação e disseminação da nova evangelização e de adaptação a diferentes públicos-alvo.

O uso da internet ainda não é uma tarefa transversal a todas as comunidades e em todas as regiões ou, como vimos, todos os concelhos do país, estando em causa fatores sociodemográficos, onde não se exclui o acesso à internet por parte das famílias portugueses e pelos mais jovens. Havendo diferenciação no uso das redes sociais, existe, porventura, um sentimento de exclusão que merece ser olhado pelas próprias comunidades católicas.

No contexto das comunidades religiosas, destrinçamos as que representam uma persistência de laços fortes com a igreja e a comunidade física, e as que, não obstante a importância da geografia e do simbolismo dos lugares sagrados, vão incorporando a internet e as redes sociais online nas suas práticas religiosas. As primeiras mantêm, como vimos, um forte enraizamento na comunidade local, uma forte participação nos grupos da paróquia e uma participação assídua na eucaristia da sua paróquia de residência (frequência pelo menos uma vez por semana na eucaristia). A relação é presencial, não havendo o recurso a mecanismos para assistir à eucaristia, optando-se pela presença física no lugar sagrado. As práticas religiosas são mais convencionais como rezar, ir à missa e rezar sozinho e em casa.

A descompactação das comunidades religiosas ocorre também pela incorporação da internet e das redes sociais nas práticas religiosas dos crentes. Embora não seja totalmente anulada a relação presencial, uma vez que persiste a presença assídua na missa dominical, por exemplo, as novas tecnologias começam a ser um complemento nas práticas religiosas que enriquecem e reforçam as experiências de fé. Em alguns contextos urbanos e nas comunidades mais abertas, por exemplo, o uso muito frequente das redes sociais e a navegação das páginas da internet, em diferentes momentos e lugares da vida quotidiana e através de diferentes dispositivos móveis, permite atualizar e densificar o conhecimento do campo religioso e permite diversificar os modos de estar e de experienciar a fé, numa forma de pertença à distância. Ou seja, o uso das redes sociais online, embora ainda de forma 
passiva (apenas consulta e não produção de conteúdos), abre novos caminhos de interação (tempos e espaços diferentes) e promovem novas sociabilidades numa comunidade territorial mais difusa e em rede.

Contudo, e esperam-se aqui estudos futuros, esta análise levanta uma questão pertinente. Noutros domínios da vida social, a incorporação das redes sociais online e das plataformas digitais seguiu uma sequência que vai da internet 1.0 às mais recentes configurações da internet 4.0 ou mesmo 5.0. Nestes casos, assistiu-se a uma progressão entre o uso de meios digitais para a transmissão unívoca de uma mensagem e etapas mais sofisticadas de diluição da fronteira entre o emissor e o recetor e a produção mais difusa de conteúdos. Nestas plataformas, os recetores não são sujeitos passivos e são, ao mesmo tempo, produtores de conteúdos, numa espacialidade flexível e multidimensional de produção de conteúdos e de comunicação.

Este não parece ser o caso das comunidades religiosas, nas quais o espaço digital e as redes sociais online promovem ainda uma comunicação verticalizada e, no caso dos recetores, mais passiva.

No entanto, o presente estudo deverá, pois, ser olhado mais como um ponto de partida do que como um ponto de chegada, sendo importante acompanhar, no futuro próximo, as novas geografias e territorialidades da população católica portuguesa.

\section{Notas}

Por decisão pessoal, os autores do texto escrevem segundo o novo acordo ortográfico.

1 Conferência Episcopal Portuguesa realizou nos anos de 1977, 1991 e 2001 um recenseamento da prática dominical, tendo como unidade de análise, todos os locais de culto dominical, incluindo a missa vespertina de sábado, tendo-se concluído, neste período temporal, a diminuição não só da população católica praticante como também da população comungante.

2 Dados fornecidos pelo Secretariado Nacional do Apostolado de Oração em Portugal.

3 Discurso do Papal João Paulo II, na Viagem Apostólica à República Dominicana, na abertura dos trabalhos da VI Conferência Geral do Episcopado Latino-Americano, 12 de outubro de 1992. Consulta na Página Oficial do Vaticano.

4 Mensagem do Papa Bento XVI para o $47^{\circ}$ Dia Mundial das Comunicações Sociais, 23 de maio de 2013. Consulta na Página Oficial do Vaticano. 


\section{Referências}

Agência Eclesia. (2018). Vaticano: Papa pede que internet e redes sociais sejam lugar de respeito pelos outros (C7vídeo). Disponível em

http://www.agencia.ecclesia.pt/portal/vaticano-papa-pede-que-internet-e-redessociais-sejam-lugar-de-respeito-pelos-outros-c-video/

Appadurai, A. (2004). Dimensões culturais da globalização. A modernidade sem peias. Lisboa: Teorema.

Barreto, A. (1995). Portugal na periferia do centro: Mudança social, 1960-1995. Análise Social, XXX(134), 841-855.

Bauman, Z. (2000). Liquid modernity. Cambridge: Cambridge Polity Press.

Bauman, Z. (2007). A vida fragmentada. Ensaios sobre a moral pós-moderna. Lisboa: Relógio D'Água.

Beck, U., Giddens, A., e Scott, L. (1997). Modernização reflexiva: Política, tradição e estética na ordem social moderna. São Paulo: Ed. Universidade Estadual Paulista.

Berry, J. (1984). Multicultural policy in Canada: A social psychological analysis. Journal of Behavioural Sciences, 16, 353-370.

Castells, M. (2001). The internet galaxy. Reflections on the internet, business and society. Oxford: Oxford University Press.

Castells, M. (2007). A galáxia internet. Reflexões sobre internet, negócios e sociedade. Lisboa: Fundação Calouste Gulbenkian, Serviço de Educação e Bolsas.

Diário de Notícias (2016, 22 de janeiro). 'As redes sociais e a internet são um presente de Deus'. Disponível em

https://www.dn.pt/sociedade/interior/as-redes-sociais-e-a-internet-sao-um-pres ente-de-deus-4993770.html, consultado a 22 de janeiro de 2018.

Ferrão, J. (2005). População e território. Em C. A. Medeiros (Dir.), T. Barata Salgueiro, e J. Ferrão (Coord.), Geografia de Portugal II. Sociedade, paisagem e cidades (pp. 50-71). Lisboa: Círculo de Leitores.

Franca, M. (2016). A expressão territorial da identidade religiosa da população católica portuguesa. Estudo de caso da diocese de Coimbra (Tese de doutoramento). Universidade de Coimbra, Faculdade de Letras, Coimbra.

Giddens, A. (1991). The consequences of modernity. Cambridge: Cambridge Polity Press.

Granovetter, M. S. (1973). The strength of weak ties. American Journal of Sociology, 78(6), 1360-1380.

Haesbaert, R. (2004). O mito da desterritorialização. Do "fim dos territórios" à multiterritorialidade. Rio de Janeiro: Bertrand Brasil.

INE (1981). XII recenseamento geral da população. II recenseamento geral da habitação 1981. Lisboa: INE.

INE. (1991). Censos 1991: XIII recenseamento geral da população; III recenseamento geral da habitação 1991, resultados definitivos. Lisboa: INE.

INE. (2001). Censos 2001: XIV recenseamento geral da população; IV recenseamento geral da habitação 2001, resultados definitivos - Portugal, Região Norte, Região Centro, Região de 
Lisboa, Região do Alentejo, Região do Algarve, Região Autónoma da Madeira, Região Autónoma dos Açores. Lisboa: INE.

INE. (2011). Censos 2011: XV recenseamento geral da população; V recenseamento geral da habitação 2011, resultados definitivos - Portugal, Região Norte, Região Centro, Região de Lisboa, Região do Alentejo, Região do Algarve, Região Autónoma da Madeira, Região Autónoma dos Açores. Lisboa: INE.

INE. (2013). Retrato territorial de Portugal 2011. Destaque à Comunicação Social 2011. Lisboa: INE.

INE. (2017). Sociedade da informação e do conhecimento. Inquérito à utilização de tecnologias da informação e da comunicação pelas famílias. Destaque à Comunicação Social. Lisboa: INE.

INE. (2018). Estimativas de população residente em Portugal. Destaque à Comunicação Social. Lisboa: INE.

Innerarity, D. (2016). A política em tempos de indignação. Lisboa: Dom Quixote.

Krejcie, R. V., e Morgan, D. W. (1970). Determining sample size for research activities. Educational and Psychological Measurement, 30, 607-610.

Levy, P. (1997). Cyberculture. Paris: Odile Jacob.

Lipovetsky, G. (2004). Hypermodern times. Cambridge: Cambridge Polity Press.

Lipovetsky, G., e Serroy, J. (2010). O ecrã global. Lisboa: Edições 70.

Massey, D. (1994). A global sense of place from space, place, and gender. Em T. S. Oakes, e P. L. Price (Eds.), The cultural geography reader (pp. 257-263). Routledge, Oxon: Ed. Taylor \& Francis e-Library.

Neto, M. (2017). Igreja e encontro na estrada digital. Perspetivas teológicas a partir do estudo de Manuel Castells. Cascais: Principia.

Oliveira, C., e Gomes, N. (2017). Indicadores de integração de imigrantes. Relatório estatístico anual 2017. Lisboa: Alto Comissariado para as Migrações.

Pew Research Center's Forum on Religion \& Public Life. (2014). Global religious diversity. Half of the most religiously diverse countries are in Asia-Pacific region. Washington: Pew Research Center.

Ribeiro, M. J. (Coord.) (2017). Relatório de imigração, fronteiras e asilo 2017. Lisboa: Serviço de Estrangeiros e Fronteiras.

Rodrigues, T., e Santos, A. (2018). Demografia política e políticas de segurança. Em T. Rodrigues, e M. Painho (Coord.), Modelos preditivos e segurança pública (pp. 57-86). Porto: Fronteira do Caos Editores.

Santos, M., Souza, M. A., e Silveira, M. L. (1998). Território, globalização e fragmentação. São Paulo: Hucitec, Anpur.

Simmel, G. (1971). "The stranger" from on individuality and social forms: Selected writings (Ed. and Trans. D. Levine). Em T. S. Oakes, e P. L. Price (Eds.), The cultural geography reader (pp. 311-315). Routledge, Oxon: Ed. Taylor \& Francis e-Library.

Teixeira, A. (2011). Identidades descompactadas: Práticas e sociabilidades crentes no campo católico. THEOLOGICA, 46(2), 249-271. 
Teixeira, A. (2012). Identidades religiosas em Portugal: Representações, valores e práticas 2011. Lisboa: UCP, Centro de Estudos e Sondagens de Opinião \& Centro de Estudos de Religiões e Cultural.

Teixeira, A. (2017). Da paróquia territorial à comunidade transterritorial. Em J. E. Franco, e J. C. S. Pereira (Dir.), Portugal católico. A beleza da diversidade (pp. 125-127). Lisboa: Círculo de Leitores.

Teixeira, A., Vilaça, H., Moniz, J. B., Coutinho, J. P., Franca, M., e Dix, S. (2019). Identidades religiosas e dinâmicas sociais na Área Metropolitana de Lisboa. Lisboa: Fundação Francisco Manuel dos Santos.

Tönnies, F. (2001). Community and civil society. Cambridge: Cambridge University Press.

Vilaça, H. (2006). Da torre de Babel às terras prometidas. Pluralismo Religioso em Portugal. Porto: Afrontamento.

Vilaça, H. (2013). Novas paisagens religiosas em Portugal: Do centro às margens. DIDASKALIA, XLIII(I.2), 81-114.

Vilaça, H., e Oliveira, M. J. (2019). A religião no espaço público português. Lisboa: Imprensa Nacional Casa da Moeda, S.A.

Virílio, P. (2000). Cibermundo: A política do pior. Lisboa: Teorema.

Virílio, P. (2006). Speed and politics. Los Angeles: Semiotext(e).

Washbourne, N. (2009). Globalisation/globality. Em D. Atkinson, P. Jackson, D. Sibley, e N. Washbourne (Eds.), Cultural geography. A critical dictionary of key concepts (pp. 161-168). Londres: I.B. Tauris \& Co Ltd.

Data de submissão: 24/04/2019 | Data de aceitação: 11/10/2019 